\title{
Condições dos treinamentos de ginastas brasileiras participantes de jogos olímpicos (1980-2004) ${ }^{1}$
}

\author{
Laurita Marconi Schiavon ${ }^{1}$ \\ Roberto Rodrigues Paes ${ }^{2}$ \\ ${ }^{1}$ Instituto de Biociências. UNESP - Universidade Estadual Paulista, Campus de Rio Claro, \\ Departamento de Educação Física, SP, Brasil \\ ${ }^{2}$ Faculdade de Educação Física, Universidade Estadual de Campinas, SP, Brasil
}

\begin{abstract}
Resumo: Este artigo tem como objetivo registrar e analisar as condições de infraestrutura dos treinamentos de ginastas brasileiras participantes de Jogos Olímpicos (1980-2004), na busca de reflexões para a modalidade de Ginástica Artística Feminina. Para tal, foi desenvolvida uma pesquisa qualitativa, que se utilizou do método de História Oral. A partir de uma análise cruzada dos depoimentos das dez ginastas colaboradoras desta pesquisa foi possível perceber que houve um aperfeiçoamento nas condições de infraestrutura a partir do início da década de 90. Este aperfeiçoamento é novamente impulsionado no final da década de 90 , com a contratação de técnicos ucranianos, o estabelecimento de uma seleção brasileira permanente e investimentos nas condições de infraestrutura de equipamentos e ginásio. Porém mesmo com a transformação positiva da modalidade nos últimos anos, todas as ginastas do estudo relataram ter passado, em algum momento, por condições não adequadas de treinamento relativas às condições de infraestrutura.
\end{abstract}

Palavras-chave: Ginástica. Educação Física e treinamento. História.

\section{Training conditions of Brazilian gymnasts who participated in the Olympic Games (1980-2004)}

\begin{abstract}
This paper aims to register and analyze the training facilities used by the Brazilian gymnasts who participated in the Olympic Games (1980-2004), in order to reflect upon this aspect of Female Artistic Gymnastics. To achieve this goal, we developed a qualitative research study using the Oral History method. Based on a cross-sectional analysis of the testimonials given by ten gymnasts who took part in this survey, we observed that training facilities have improved since the 90's, when Ucranian coaches were hired, a permanent Brazilian team was established and investments were made on equipment and training facilities. Despite the positive changes we have witnessed in this sport in the past years, all gymnasts who participated in the study reported that they had to practice in inappropriate training facilities at some point.
\end{abstract}

Keywords: Gymnastics. Physical Education and training. History.

\section{Introdução}

O presente artigo aborda as condições de infraestrutura dos treinamentos em ginástica artística feminina (GAF) durante a carreira desportiva das dez ginastas brasileiras participantes de Jogos Olímpicos no período de 1980 a 2004. Ele é derivado de uma pesquisa mais ampla desenvolvida como tese de doutorado "Ginástica Artística e História Oral: a formação desportiva de ginastas brasileiras participantes de Jogos Olímpicos (1980-2004)" ( 2009).

Tendo carência de estudos que abordem este assunto no Brasil, este artigo tem o objetivo de

\footnotetext{
Trabalho derivado da tese de doutorado defendida na faculdade de Educação Física da Universidade Estadual de Campinas/UNICAMP em 2009.
}

registrar e analisar as condições de infraestrutura de treinamento e fatos relativos a esse tema, a partir do relato das ginastas colaboradoras desta pesquisa sobre suas carreiras desportivas, ou seja, tendo como ponto de vista a visão das mesmas.

Entre os muitos aspectos que envolvem a preparação desportiva de ginastas de alto rendimento desportivo, a questão da infraestrutura é um dos aspectos importantes ( $\underline{D E}$ BOSSCHER et al, 2009).

O sistema desportivo, segundo Digel (2002), depende de alguns recursos necessários para se desenvolver: tradição olímpica ou condições históricas específicas, base ideológica, interesse e participação nos desportos, estrutura organizacional, estrutura de pessoal (funcionários e voluntários), finanças, atletas, técnicos, 
identificação de talento, promoção de talento, treinamento, competições, reuniões desportivas, sistema de prêmio para atletas, sistema de prêmio para técnicos, seguro social para atletas, seguro social para técnicos, luta contra o doping, prioridades e esquemas, tendências e aspectos específicos de cada nação.

Digel (2002) estuda os sistemas desportivos de oito nações que se destacam em diferentes desportos: Estados Unidos, Rússia, Alemanha, Itália, Austrália, China e Reino Unido e verifica que entre essas potências mundiais desportivas, apenas os Estados Unidos não possuem significativo envolvimento do Estado ou de um sistema político desportivo, mas ao mesmo tempo possuem uma cultura de estreita relação entre desportos e escolas.

Como exemplo do apoio e envolvimento significativos do Estado, temos o Reino Unido, que após a classificação de $36^{\circ}$ lugar nos JO de Barcelona, resolveu investir fortemente na parte desportiva, contratando profissionais australianos que já desenvolviam um modelo de sucesso em seu país (ENGLISH INSTITUTE OF SPORT, 2008). O número de escolas de desporto tem crescido no Reino Unido, que em setembro de 1997 eram onze, aumentaram para 67 no ano 2000, com previsão de 150 em 2004. Os especialistas dividiram o Reino Unido em sete regiões para ter uma melhor administração dessa parte desportiva que tem sido apoiada financeiramente por verbas vindas de jogos de loteria (DIGEL, 2002).

De acordo com o mesmo autor, a Rússia, apesar da diminuição do apoio financeiro e a consequente diminuição da qualidade de suas escolas de desporto, possui um forte sistema desportivo, ainda funcionando com o sucesso de grandes atletas. Sua estrutura em 1999 era de 2113 escolas de desporto, com uma etapa posterior de atletas chamada de Escola de desporto "Reserva Olímpica". Após esse nível ainda há as escolas de desporto de alto rendimento e, finalmente, os centros de atletas em condições de disputar vagas na seleção russa para JO.

Talvez esse sistema possa ser comparado somente ao da China atualmente, que tem toda a sua estrutura desportiva apoiada no Estado (DIGEL, 2002).
Digel (2002) aponta que a China possuía, em 1998, 35 Institutos de técnica desportiva, que são os principais no país, com 31000 atletas para 4071 técnicos nestes centros. Além disso, havia mais 3800 escolas de desporto com quatro níveis diferentes.

Mais especificamente abordando a infraestrutura de ginásios de ginástica artística

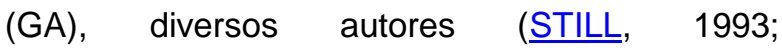
SMOLEUSKIY, GAVERDOUSKIY, 1996; ARKAEV; SUCHILIN, 2004) ressaltam a importância de aparelhagem e materiais adequados, devido à segurança dos ginastas em uma modalidade que envolve riscos de acidentes pela sua característica própria de inverter o corpo e realizar acrobacias e movimentos diferentes do cotidiano. Still (1993) considera que um ginásio de GA deve ter toda a aparelhagem preparada para o uso e com todas as condições de segurança, enfatizando que entre os fatores estruturais que podem causar algum prejuízo para um ginasta estão: o edifício ou espaço do ginásio, a aparelhagem específica da modalidade e outros equipamentos auxiliares no local. Arkaev e Suchilin (2004) destacam também a utilização de aparelhagens reconhecidas pela Federação Internacional de Ginástica, por possuírem tecnologias desenvolvidas para absorção de impacto e diminuição de lesões nos ginastas.

Segundo Bortoleto (2004), o governo da Espanha vem progressivamente investindo em instalações desportivas, pois em 1968 cria um "Plano Ideal de Instalações Desportivas" e em 1978, o Conselho Superior de Desporto, complementando o plano anterior, disserta sobre a necessidade da construção de Centros de Alto Rendimento (CAR), Centros de iniciação técnico desportiva (CITD) e centros de promoção técnico desportiva (CPTD), efetivados na década de 80 . Os resultados destes investimentos foram nítidos, assim como o autor ressalta: "esforço recompensado durante as olimpíadas de Barcelona com a melhor participação da equipe espanhola de todos os tempos em um evento desta natureza" (p.317).

O Comitê Organizador dos Jogos Olímpicos e Paralímpicos Rio 2016 em documento que elenca os requerimentos gerais e técnicos mínimos necessários para que uma instalação esportiva possa atender às expectativas de demandas dos atletas, expõe os equipamentos necessários para 
adequado desenvolvimento da modalidade de GAF:

Um conjunto completo de equipamentos para Ginástica Artística Feminina (todos os equipamentos devem estar de acordo com as especificações da Federação Internacional de Ginástica), sala de treinamento de força completa, sala para os serviços de fisioterapia e massagem, facilidade de fornecimento de gelo nas áreas de fisioterapia e massagem (máquina de gelo), pequena sala de conferência com equipamento multimídia (para filmagem e projeção), vestiários próximos à área de treinamento, com chuveiros e área seca, sanitários próximos à área de treinamento (RIO2016, 2011, p.30).

No Brasil, as instituições desportivas que organizam a GA nos estados e nacionalmente não têm demonstrado e realizado um efetivo sistema que organize e coordene a atuação dos técnicos ou ofereça condições mínimas de infraestrutura para a prática da modalidade em diferentes regiões do país.

Mais recentemente em 1999 foi instalado em Curitiba-PR, sede da Confederação Brasileira de Ginástica (CBG) naquele momento, e local onde a seleção brasileira de GAF treinou em regime de internato desde 1999 até os Jogos Olímpicos de 2008, o Centro de Excelência de Ginástica. Segundo Carvalho (2007):

\begin{abstract}
Com uma infraestrutura altamente desenvolvida, encontra-se 0 Centro de Excelência de Ginástica, o qual conta com equipamentos oficiais e auxiliares distribuídos em dois ginásios de sessenta por trinta e seis metros cada qual, e uma equipe multidisciplinar formada por treinadores especialistas nacionais e internacionais, médicos, fisioterapeutas, psicólogos, nutricionistas, coreógrafos e coordenadores que gerenciam as demandas das seleções permanentes de GA (p.25).
\end{abstract}

Em relação às condições de infraestrutura no Brasil, durante a carreira desportiva das ginastas foi possível revelar a partir da visão das mesmas, que, todas, independente da geração a que pertenceram, passaram em algum momento por condições que não eram as ideais, muitas vezes podendo ser consideradas condições precárias de treinamento, se comparadas às condições do Centro de Treinamento de Curitiba, chamado de Centro de Excelência, que segundo Carvalho (2007) e Vieira e Freitas (2007 apud NUNOMURA; OLIVEIRA, 2012) possui uma infraestrutura de alto nível.

\section{Método}

Para o desenvolvimento desta pesquisa qualitativa foi utilizado o método de História Oral
(MEIHY, 2005; SIMSON, 1988; THOMPSON, 1992). O método utilizado baseia-se na possibilidade de receber informações de pessoas que participaram desses importantes períodos da Ginástica Artística Feminina (GAF) no Brasil, reconstruindo 0 processo de formação de ginastas (QUEIROZ, 1988). Segundo Queiroz (1988, p.19):

\begin{abstract}
História oral é um termo amplo que recobre uma quantidade de relatos a respeito de fatos não registrados por outro tipo de documentação ou cuja documentação se quer completar. Colhida por meio de entrevistas de variada forma, ela registra a experiência de um só individuo ou de diversos indivíduos de uma mesma coletividade. Neste último caso buscase a convergência de relatos sobre um mesmo acontecimento ou sobre um período do tempo.
\end{abstract}

Recorreu-se à utilização desse método, principalmente por não haver registros disponíveis sobre a formação desportiva destas ginastas por meio de documentos ou de outras pesquisas publicadas, além disso, é possível a partir do referido método o levantamento de informações detalhadas referente aos acontecimentos vividos na carreira desportiva de cada uma das ginastas que de outra forma poderiam ter passado despercebidas.

Portelli (1997) ressalta que o diferencial da utilização deste método é a "subjetividade do expositor" e comenta posteriormente: "fontes orais contam-nos não apenas o que o povo fez, mas o que queria fazer, o que acreditava estar fazendo e o que agora pensa que fez" (p.31). Laville e Dionne (1999) corroboram esta afirmação:

Uma maneira conhecida e comprovada, própria das ciências humanas, de obter informação, consiste em colher os depoimentos de pessoas que detêm essa informação. $O$ recurso a esses depoimentos permite a exploração dos conhecimentos das pessoas, mas também de suas representações, crenças, valores, opiniões, sentimentos, esperanças, desejos, projetos, etc. (p, 183).

Entre as várias técnicas de desenvolvimento do método de História Oral, o "depoimento oral" foi utilizado nesta pesquisa. No depoimento oral, o pesquisador propõe um tema para organizar o relato de vida das pessoas que serão estudadas (QUEIROZ, 1988, p.21). A pesquisa, de forma mais ampla, está focalizada em um determinado tema, a "história de vida esportiva" destas ginastas, e mais especificamente neste artigo, o tema discorrido, gerado a partir dos depoimentos 
é "estrutura física dos lugares que desenvolveram seus treinamentos".

Participaram da pesquisa dez ginastas, apresentadas a seguir em ordem cronológica de participação em Jogos Olímpicos: Cláudia Magalhães (1980), Tatiana Figueiredo (1984), Luisa Parente (1988 e 1992), Soraya Carvalho (1996), Daniele Hypólito (2000, 2004 e 2008), Camila Comin (2000 e 2004), Ana Paula Rodrigues (2004), Caroline Molinari (2004), Daiane dos Santos (2004 e 2008) e Laís Souza (2004 e 2008) $)^{2}$. O critério estabelecido para determinar o universo da pesquisa foi: ginastas brasileiras participantes (ou classificadas) dos Jogos Olímpicos, na modalidade de Ginástica Artística Feminina até o ano de 2004.

Segundo Queiroz (1988), as entrevistas, no caso de depoimentos orais, são diretamente dirigidas pelo pesquisador, e foram utilizadas entrevistas não estruturadas:

na qual o entrevistador apoia-se em um ou vários temas e talvez em algumas perguntas iniciais, previstas antecipadamente, para improvisar em seguida suas outras perguntas em função de suas intenções e das respostas obtidas de seu interlocutor". (LAVILLE; DIONNE, 1999, p.190).

O primeiro momento da entrevista é feito de forma bastante livre, a partir de um tema amplo, que nesta pesquisa foi a história desportiva de cada ginasta (SIMSON, 2006). Num segundo momento, o pesquisador levanta temas geradores, direcionando para assuntos relevantes da história desportiva do colaborador, com o propósito de aprofundar mais sobre determinados assuntos e lembrá-lo de fatos que, muitas vezes, o próprio atleta não valoriza como parte de sua história pessoal, ou não se aprofundou o suficiente ao falar livremente, ou seja, assuntos que interessam à pesquisa. Para este momento da entrevista há um roteiro, elaborado com foco em momentos de destaque da formação desportiva destas ginastas, sendo no caso deste artigo, o tema gerador "estrutura física dos lugares que desenvolveram seus treinamentos".

Os depoimentos transcritos foram classificados em unidades de análise, ou seja,

\footnotetext{
${ }^{2}$ As ginastas autorizaram o uso de seus nomes para fins científicos, informação importante para estudos de História Oral, os quais normalmente têm os nomes dos sujeitos expostos, devido à importância dos mesmos. Por não serem numerosos os sujeitos neste tipo de pesquisa qualitativa, é importante destacar a relevância dos mesmos no contexto da pesquisa, neste caso sobre a Ginástica Artística Feminina no Brasil.
}

"recortes que agrupam em função de sua significação, que cumpre que esses sejam portadores de sentido em relação ao material analisado e às intenções da pesquisa" (LAVILLE; DIONNE, 1999, p.216). A cada unidade de análise foram agrupados os relatos que as atletas proporcionavam sobre esse mesmo tema, sendo neste artigo apresentada a unidade de análise: condições de infraestrutura dos treinamentos.

As transcrições de cada entrevista estão disponibilizadas no Laboratório de História Oral (LAHO) do Centro de Memória da Universidade Estadual de Campinas (UNICAMP).

Esta pesquisa foi previamente aprovada pelo Comitê de Ética em pesquisa da Faculdade de Ciências Médicas da Universidade Estadual de Campinas em 27 de março de 2007, tendo o número de parecer: 136/2007.

\section{Análise cruzada dos dados}

Entre as formas que a história oral pode ser construída a análise cruzada foi a técnica utilizada nesta pesquisa (THOMPSON, 2002).

$\mathrm{Na}$ análise cruzada "a evidência oral é tratada como fonte de informações a partir da qual se organiza um texto expositivo" (THOMPSON, 2002, p.304). Sempre que o objetivo primordial passe a ser a análise e não a apresentação de histórias de vida integrais, “a forma global já não pode ser orientada pela história de vida como forma de evidência, mas deve emergir da lógica interna da exposição" (THOMPSON, 2002, p.304). Em geral, comparando a evidência de uma entrevista com a de outra, e associada à evidência proveniente de outras fontes, sempre que possível (THOMPSON, 2002).

A análise da pesquisa foi realizada a partir dos dados coletados pela pesquisa de campo nos depoimentos das colaboradoras por temas, as unidades de análise, neste caso, as condições de infraestrutura de treinamento das ginastas. Posteriormente, as informações de cada ginasta foram cruzadas para ser possível estabelecer relações entre elas e, a partir disso, confrontá-las, destacando e refletindo sobre as diferenças e, principalmente, as semelhanças nas condições de infraestrutura na preparação desportiva das ginastas colaboradoras desta pesquisa (THOMPSON, 2002; SIMSON, 2006).

A partir disso foi feita a análise comparativa e discussão dos dados dos depoimentos, utilizandose do embasamento proveniente das informações 
levantadas na literatura estudada, discordando, confirmando, ou mesmo oferecendo colaborações com novas abordagens, a principal contribuição da História Oral ao trazer informações que não constem em registros oficiais ou mesmo discordando dos registros existentes, como uma evidência nova, que pode indicar o caminho para uma nova interpretação (THOMPSON, 2002).
Para a comparação entre as colaboradoras deste estudo, as mesmas foram agrupadas por semelhanças de suas histórias como um todo, característica inerente à história oral como forma de avaliação da coerência dos depoimentos (THOMPSON, 2002). Deste modo, emergiram três grupos distintos (Quadro 1) e em seguida a análise foi realizada também segundo este agrupamento.

Quadro 1. Grupos de Ginastas da pesquisa separadas por semelhanças de cada época.

\begin{tabular}{|l|c|}
\hline \multicolumn{1}{|c|}{ Grupo } & Ginastas \\
\hline $\begin{array}{l}\text { Ginastas Pioneiras: foram as primeiras ginastas que representaram o Brasil em Jogos } \\
\text { Olímpicos (JO), principalmente na década de 1980. Essas ginastas, em relação às das } \\
\text { gerações posteriores, viveram situações de menor apoio dado ao sistema de treinos, no que } \\
\text { se refere às condições financeiras, material e de recursos humanos. Houve carência de apoio } \\
\text { nesses aspectos, tanto em seus clubes, como também na seleção brasileira. Estas ginastas } \\
\text { buscavam uma boa participação nos JO, no entanto sem chances concretas de disputa de } \\
\text { medalhas, ou mesmo de uma final olímpica. }\end{array}$ & 3 \\
\hline $\begin{array}{l}\text { Ginastas de Transição: esse grupo viveu uma fase sem apoios e estrutura, num determinado } \\
\text { momento, semelhante ao que foi experimentado pelas ginastas pioneiras, contudo, } \\
\text { posteriormente elas tiveram a oportunidade de viver uma fase de maior apoio. As ginastas } \\
\text { desse grupo, inclusive, participaram das primeiras conquistas brasileiras de destaque nas } \\
\text { competições internacionais. }\end{array}$ & 4 \\
\hline $\begin{array}{l}\text { Ginastas da Nova Geração: fazem parte desse grupo as ginastas que desde que chegaram à } \\
\text { seleção brasileira já se depararam com condições de excelência para uma adequada } \\
\text { preparação desportiva, nos moldes de potências mundiais que disputam medalhas em } \\
\text { Campeonatos Mundiais e JO. }\end{array}$ & 3 \\
\hline
\end{tabular}

\section{Apresentação da análise cruzada ${ }^{3}$}

Com o aperfeiçoamento da estrutura da seleção brasileira de GAF nos últimos dez anos, mencionada anteriormente, quanto mais contemporâneas as ginastas, de acordo com o depoimento das ginastas, menos tempo permaneceram em situações não adequadas de treinamento, mas todas, em algum momento de suas carreiras desportivas, passaram por condições não adequadas de treinamento. Essa comparação de condições tem como base os preceitos apresentados anteriormente pela Organização dos Jogos Olímpicos de 2016, que relata como condição mínima, possuir os aparelhos oficiais da modalidade regulamentados pela FIG (IO2016, 2011).

De acordo com as ginastas pioneiras, as três relatam terem vivido situações com dificuldades básicas de aparelhagem até mesmo quando estavam se preparando para Campeonatos

\footnotetext{
${ }^{3}$ É importante destacar que todas as discussões partem de depoimentos que trazem evidências a partir da visão das próprias ginastas que viveram este processo, sendo três das dez ginastas ainda atletas no momento da coleta e sete delas já tendo encerrado suas carreiras. Todas maiores de idade.
}

Mundiais (CM) e Jogos Olímpicos (JO). Uma das ginastas deste grupo expõe que não tinha tablado ${ }^{4}$ para o treinamento da prova de Solo na sua preparação para os JO de Seul (1988):

Tinha uma época que a gente não tinha tablado ainda e treinava só "marcando" ${ }^{\text {a }}$ a série. De tanto treinar assim, na hora da competição eu "marquei" a série também (risos). Foi no estadual. $O$ arbitro viu quando terminei a "marcação da acrobacia" correndo, olhei para um lado, olhei para o outro e fiquei parada. Depois deixaram eu recomeçar. Interessante...

E depois até Seul não tinha tablado para treinar. Então eu treinava coreografia na sala de balé e treinava aquela série vai e vem de pista de Solo (sem tablado). Então era uma época ainda sem apoio, sem condições ideais de treinamento.

Outra ginasta do mesmo grupo também comenta sobre a falta de condições adequadas no Brasil nas décadas de 70 e 80 :

Em relação aos aparelhos, no Tijuca Tênis Clube não tinha tablado. Era só uma passadeira de sarneige. Eram duas camadas de sarneiges

\footnotetext{
${ }^{4}$ Aparelho oficial da prova de Solo, em formato quadrado com $12 \mathrm{~m}$ em cada lateral.

${ }^{5}$ Expressão que significa que não fazia as acrobacias nos treinamentos de séries, apenas a parte coreográfica e de exercícios de dança (saltos e giros).
} 
para amortecer. A gente colocava, aquele esquema de por a prancha (trampolim) no final da passadeira (risos). Marcava para chegar com o pé lá no final na prancha e cair no colchão fofo. Para conseguir saltar mais. Fazia só as diagonais e o resto era no chão. Para dar para marcar alguma coisa. Tablado só quando fui para os Estados Unidos. Não, no CEFAM tinha tablado também. Depois nos Estados Unidos e no Flamengo também tinha depois quando voltei dos Estados Unidos. Mas mesmo assim no Flamengo na época não era um tablado de boa condição, boa qualidade, então a gente mesmo assim fazia as diagonais com colchões extras. Nos EUA não. Lá era fantástico!

Atualmente, o Clube de Regatas do Flamengo, onde treinam Daniele Hypólito e Jade Barbosa ${ }^{6}$, apresenta boas condições de treinamento, que se aproximam às requeridas pelo comitê organizador dos JO - RIO2016, e continua a formar ginastas de destaque em todas as categorias, mas as condições de infraestrutura nem sempre foram como as atuais:

Em relação a apoios recebidos, sempre foi duro. A gente treinava em condições péssimas. E era a melhor condição do Brasil, mas era péssima. O que nos revoltava, acho que mais era porque a gente sabia que estava muito aquém da condição ideal, porque a gente já tinha viajado. Então até eu viajar pela primeira vez (risos), aqui era maravilhoso, realmente.

Aqui no Flamengo, o ginásio tinha um tablado da Copa do Mundo de 76. Sei lá. [...] Então era um tablado que nas pontas, cada placa já não se encontrava mais, cheio de buracos. Porque fora isso, antes era pista. Então não dava para fazer solo neste tablado. A gente fazia um " $x$ " depois deste tempo, um " $x$ " com sarneiges, para poder fazer ali. Nossa uma loucura! Aí tinha o fosso ${ }^{7}$. Depois de um tempo o Flamengo fez um fosso.

Então, até, por exemplo, até o campeonato sulamericano de 1984, era num outro ginásio, muito menor, não tinha tablado, era só uma passadeira. Aquele ginásio que dividia com o basquete. A gente corria do lado da quadra de Basquete e ia saltar lá na sala da Ginástica. E aí no meio a gente botava magnésio para dividir e a bola de basquete ia no meio da nossa corrida. Então era só a pista de solo. E alguns aparelhos do masculino, por exemplo, tinham que ser montados num dia, desmontados no outro porque não cabiam todos num dia só. Então tinham dias que eles faziam Argolas, tinham dias que eles faziam Barra, o nosso por acaso ficava tudo montado. Só o Salto que montava e desmontava também conforme a necessidade. Aí depois então, foi para o outro

\footnotetext{
6 Ginasta $10^{\text {a }}$ colocada nos JO de Pequim (2008) e medalhista de bronze no CM de 2007, ambas as classificações na Cll (individual geral).

${ }^{7}$ Um grande buraco, como uma "piscina", cheio de blocos de espuma, utilizado para aprendizagem de exercícios de maior risco, onde os ginastas podem cair de diferentes formas sem sofrerem lesões.
}

ginásio, ganhou, conquistou um ginásio só, com fosso e tudo mais. Nossa, era uma estrutura e tanto! Mas foi difícil porque queriam botar patinação ou futsal ali. E foi dura a briga para conseguir. Deve ter sido em 86 que fomos para esse ginásio (Ginasta do Grupo de Pioneiras).

Ainda no grupo de ginastas pioneiras, uma delas também aborda as dificuldades e comenta sobre uma iniciativa de melhorar as condições da GA no Brasil, já na década de 80 , com o Projeto Impacto, um centro de treinamento de ginastas no Rio de Janeiro com bons materiais e técnicos estrangeiros:

Eles reuniram as melhores atletas do Brasil para conquistar uma medalha olímpica de ouro. Esse era um projeto patrocinado por um colégio. Juntaram todo mundo num lugar de treinamento, como Curitiba. Era no CEFAM que é na Avenida Brasil (RJ). Contrataram técnico, uma equipe toda de psicólogos, médicos. Foi bem bacana! Isso acho que foi em 80,81 . Aí a gente ficou todo mundo treinando lá, só que o projeto acabou. Durou, acho que um ano e meio mais ou menos.

Essa iniciativa, sem uma estrutura que oferecesse continuidade neste processo fez com que esta ginasta buscasse a estrutura almejada em outro lugar. No Brasil, o melhor centro, segundo depoimento anteriormente citado, era o Clube de Regatas do Flamengo, o que na época também não correspondia às expectativas do alto rendimento desportivo. Então esta ginasta foi para os Estados Unidos, patrocinada pela sua própria família, onde se preparou para classificar-se para os JO de Los Angeles (1984).

Acho que foi em 82, 83. Acho que eu tinha treze anos. Eu fui morar nos Estados Unidos. Eu fiquei sozinha. Meu pai foi comigo, foi ver se estava tudo bem. Aí eu fiquei lá sozinha com outras atletas que também treinavam. $\mathrm{Na}$ época era o melhor centro lá. Depois teve o Karoly (técnico da Nádia Comaneci). Então tinham atletas dos Estados Unidos inteiro morando lá. Na casa do treinador mesmo, Dick Monvisiel.

Fiquei lá um ano e meio. Fiquei até 83 , quando eu consegui a classificação para as Olimpíadas. Depois eu não aguentei mais, voltei para o Brasil. Porque o treino era muito puxado na época. [...] Então... longe de casa... tudo isso. Eu fiquei lá um ano e meio, depois eu voltei. Quando eu voltei, eu já fui para o Flamengo, que já era o melhor clube na época (p.195).

No mesmo grupo de pioneiras, outra ginasta não diz passar tantas dificuldades na época, treinando na Universidade Gama Filho: "Naquela época era maravilhoso o apoio ao esporte, na época do ministro Gama Filho, era tudo perfeito no esquema que qualquer atleta precisava.". E 
expõe as condições de aparelhagem que possuíam:

Era muito bom, tinham todos os aparelhos, a paralela nova chegou e comprava barrote novo de fibra de vidro, vinha da Alemanha, a Gama Filho sempre tinha. Eu acho que era no Brasil, tudo a mesma coisa em relação à aparelhagem. A gente tinha na Gama Filho o tablado mais moderno que existia e tinha no Brasil todo. Mas era daquele primeiro amarelo que tinha que bater com a vassoura e martelar e prender os ferrinhos. Quando começava a ficar quebradinho, botava colchão na pista do centro e depois inventaram o tablado com molas. Eu acho que a gente colocou, construiu com as molas com chapinha, todo mundo construindo. Teve uma coisa de copiar e adaptar uma coisa que a gente sabia que já existia no mundo, nos outros países. Depois foi evoluindo. Quando a gente foi para o Flamengo tinha quase a mesma coisa porque os campeonatos que tinham no Flamengo, na Gama Filho e na Tijuca, eram os mesmos aparelhos. Devia ter na Gama Filho umas três traves, uma baixinha, uma média e uma maior, tinha sempre uma que era melhor. E também vendiam as capas de trave internacionais que a gente comprava quando viajava. A gente cobria a trave, porque eu aprendi tudo naquelas de madeira: rolamento, flic, tudo na de madeira, ponte. Nos campeonatos internacionais as traves eram fofinhas (risos); nossa senhora, uma beleza! Aí a gente comprou a capa e voltava para casa com a capinha.

Mesmo esta ginasta não tendo reclamado das condições de infraestrutura do ginásio em que treinou a maior parte de sua carreira, é possível perceber que, em relação ao nível internacional, exposto pelas próprias ginastas desta geração, havia certa distância do alto rendimento desportivo. A mesma ginasta falando de seus treinos expõe as condições não tão satisfatórias:

No início eram os aparelhos e a gente fazia muito solo, solo era o predileto do técnico (risos) e o predileto de todo mundo e era festa, quando era solo, era tumbling (acrobacias) para os meninos e para as meninas, como se fosse auge do treinamento e ai todo mundo fazia solo junto naquela pista do tatame duro "pra caramba" de sarneige e aqueles colchões todos, muito minitrampolim até no aquecimento, corrida, minitrampolim, mortal, salto esticado, mistura de corrida com minitrampolim. Era diversão e a gente aprendia muito duplo, pirueta, tudo para frente, tinha muito treinamento de minitrampolim para trás para a gente aprender. Não tinha cama elástica, eu treinei a vida inteira sem cama elástica até aos 22 anos, quando eu fui para o Flamengo. Tanto que eu não tinha nenhum talento na cama elástica no fim da minha carreira, eu tinha pavor, não cresci fazendo cama elástica (risos). Enquanto o pessoal do Flamengo sempre teve, desde neném.

Estes depoimentos são corroborados por Oliveira e Bortoleto (2009) ao registrarem as condições da ginástica artística masculina (GAM), abordando a GAF em alguns momentos de sua pesquisa, quando expõem que:

na década de 80 , havia poucos centros esportivos que desenvolviam projetos de GA, sendo que a grande maioria dos que existiam não podiam fornecer um treinamento adequado para os nossos atletas chegarem ao alto nível, seja por dificuldades de infraestrutura ou de aperfeiçoamento técnico. Nesta época, a maior parte dos clubes não possuía recursos financeiros suficientes para comprar ou fazer a manutenção dos aparelhos e equipamentos auxiliares, em sua maioria importados, dificultando a progressão técnica dos ginastas com segurança, eficiência e rapidez. (p.304305)

Já no grupo de ginastas de transição, temos diferentes experiências, mas sempre passando, em algum momento, por alguma condição de treinamento que não apresenta condições satisfatórias para a preparação desportiva das melhores ginastas do país.

A primeira ginasta, após as pioneiras, retrata bem esse processo de transição, pois ainda vive muitas experiências que se assemelham ao período anterior e, ao mesmo tempo, beneficia-se de um processo mais amadurecido e organizado no apoio à GA brasileira, principalmente em relação às condições de infraestrutura.

Esta ginasta talvez seja entre as atletas desta pesquisa, o caso mais curioso e particular de todas, pois treinou na academia de seu pai e patrocinada totalmente por ele, tanto em relação ao local de treinamento, com aparelhagem construída pelo próprio pai, como em viagens e competições, durante os cinco primeiros anos de sua carreira de ginasta, como ela mesma relata:

No início era uma coisa assim, bem divertida. [...] Os aparelhos eram bem adaptados. Eu acho que eu fui boa ginasta de trave porque a trave que meu pai construiu era muito fina. Porque, realmente, a trave oficial tem dez centímetros, mas ela é abaulada nas laterais, então você tem a impressão que ela é mais gordinha. A minha era $10 \mathrm{~cm}$ e era mais fina depois. Então, quando eu chegava na competição, eu achava enorme, eu pensava que estava num banco sueco. Era um aparelho bem amador mesmo.

Olha a parte de material era aquilo. Começou no tatame, depois meu pai foi, colocou aquela barrinha que colocam no teto. Que eu lembro tinha o tatame, tinha essa barrinha, aí construiu um plinto, um trampolim, aí um tempo depois, sim, teve trave alta, a gente tinha o colchão "gordo", tinha paralelas que ele construiu também, tinha um cavalo, tinham todos os

\footnotetext{
${ }^{8}$ Colchão para aterrissagem com $30 \mathrm{~cm}$ de espessura.
} 
aparelhos. E isso eu passei bastante tempo. Os cinco anos que eu treinei com meu pai foram assim. Fui campeã em campeonatos internacionais treinando lá, sul-americano, copas internacionais, etc.

[...] Quando fui para São Paulo já tinha tudo. Lá no Pinheiros tinha o solo, o solo completo que é o tablado, o meu em Brasília era pista. Aquela pista tinha só duas placas de molas que meu pai construiu também. Foi ele que via assim: ah! Essa mola tinha esse tamanho, tinha uma madeira e uma espuma de densidade super baixa assim. Então, eu tinha problema no pé. Tinha muitas dores, porque era muito impacto.

Além dessa precariedade de aparelhos amadores, construídos pelo seu pai, a ginasta tinha o problema de não ter muitas vezes um local fixo para treinar, pois a academia foi ficando pequena, mas seu pai sempre se esforçava para resolver o problema. É realmente difícil pensar que esse tipo de estrutura tenha gerado uma ginasta classificada para os $\mathrm{JO}$, o que reflete uma falta de estrutura do país para com o desporto naquele momento. Ela relata sobre seu pai e essas condições:

Eu o via muito empolgado, muito determinado, muito esforçado para construir material. Às vezes, a gente não tinha lugar fixo para treinar. A gente tinha um clube, de repente o clube: "ah... não quero mais vocês aqui não. Vão para outro lugar". E nesses clubes, a gente treinava no salão de festas. Então tinha que montar e desmontar, montar e desmontar os aparelhos. Aí eu via meu pai com o colchão "gordo" em cima do carro dele, indo para outro lugar, os aparelhos dentro do carro. Então era assim, uma mão de obra (p.197).

Entre os relatos de condições de infraestrutura, talvez a situação mais inadequada do ponto de vista de condições para o desenvolvimento de ginastas de alto rendimento desportivo, conforme já mencionado, seja a desta ginasta.

A literatura confirma este tipo de situação na mesma época quando relata: "Neste período não só os atletas e clubes sofriam com o amadorismo e a falta de investimentos na modalidade, mas a própria $\mathrm{CBG}$ tinha problemas organizacionais severos" (OLIVEIRA; BORTOLETO, 2009, p.305). De acordo com Vicelli (2008 apud OLIVEIRA; BORTOLETO, 2009, p.305) "o amadorismo da modalidade era tão grande que no início da década de 90 , os documentos da CBG eram guardados no porta-malas do carro da então presidente Vicélia Florenzano que assumiu seu primeiro mandato em 1991".
$\mathrm{Na}$ mesma geração, as outras três ginastas mencionam as condições que vivenciaram:

Em Santo André não tinha muita condição, assim, lembrando da aparelhagem. Até não lembro muito assim da aparelhagem porque faz muito tempo, mas uma coisa que eu fico sempre na cabeça era o solo, que era de tatame $^{9}$. Era um tatame de judô em que a gente fazia o nosso treino de solo.

Então em relação à estrutura física de onde eu comecei, para a iniciação era boa. Tinha tablado, tinha fosso, paralela, solo. Era bem legal assim. O espaço era grande e era público! Nesse lugar tinham vários tipos de esporte. Tinha vôlei, basquete, só não tinha natação, se eu não me engano. Judô, atletismo, essa coisa toda. Eles até trabalhavam com paraolímpico. Então eu comecei nesse centro e tinha estrutura sim, uma estrutura boa. Não era de alto nível como tem aqui na seleção brasileira, mas era um lugar bacana assim para treinar.

Eu comecei a treinar com cinco anos em uma praça pública em Curitiba onde a estrutura era muito precária, mas era o único local em Curitiba que havia $\mathrm{GO}^{10}$. Tinham todos os aparelhos: o salto, a trave e a paralela, mas eram quase que condições mínimas para fazer ginástica. Então quando eu mudei para essa outra escola de ginástica, que eu melhorei de nível, que era um segundo colégio particular. [...] Então foi bem difícil assim no começo eu não tinha estrutura médica, não tinha aparelhos apropriados, era aquela estrutura de aparelhos de 20 anos. Então a gente treinava em um colégio, onde ficavam os aparelhos: Bom Jesus da Aldeia, aqui em Curitiba, que era onde a Soraya Carvalho treinava quando vinha para Curitiba preparando-se para os JO. Então a gente começou a treinar nesses aparelhos.

$\mathrm{Na}$ etapa de preparação desportiva preliminar das ginastas do grupo de transição, uma delas expressa menos dificuldades em relação à infraestrutura durante a sua carreira, pois sua iniciação no Centro Estadual de Treinamento Esportivo/RS (CETE) ofereceu-Ihe boas condições para o trabalho de base, onde ela permaneceu por aproximadamente um ano e foi posteriormente indicada ao clube Grêmio Náutico União, em Porto Alegre, que também oferecia uma boa infraestrutura, considerando seu depoimento: "Então, no União, os aparelhos eram melhores do que lá (CETE) e o nível já era diferente de lá também".

As outras duas ginastas desta mesma geração também passaram por um local de iniciação desportiva, durante a etapa de preparação preliminar, e deram início aos seus treinamentos,

\footnotetext{
${ }^{9}$ Material utilizado para Judô, feito de palha prensada na época.

GO - Ginástica Olímpica, nomenclatura utilizada anteriormente para a Ginástica Artística no Brasil.
} 
já na etapa de especialização inicial (ZAKHAROV; GOMES, 2003), no mesmo local, mas não durante muito tempo, pois foram indicadas para outras entidades que ofereciam uma estrutura técnica e de infraestrutura superior.

Uma das ginastas passou pela Academia Yashi, na cidade de São Paulo, que não é muito comentada em seu depoimento, talvez por ter permanecido apenas um ano e, em seguida, foi para o Clube de Regatas do Flamengo, a convite da técnica principal de GA do clube. Ela explica sobre as suas condições de infraestrutura:

As estruturas físicas, do Flamengo e de Santo André, eram bem diferentes. [...] A estrutura de aparelhos, a estrutura física do ginásio do Flamengo tinha uma coisa muito importante que é o fosso, que para a ginástica é uma parte do ginásio que é indispensável, porque é onde, teoricamente você se "joga" num bando de espuma para aprender as coisas. Se "joga", porque sempre tem a ajuda do treinador, tudo, porque uma parte muito importante também da ginástica é o treinador. Porque é um esporte que é muito clínico. Então, às vezes a gente faz uma coisa que a gente acha que foi excelente, mas o treinador consegue enxergar os mínimos detalhes daquele elemento que a gente está executando. Então um fosso nesse sentido é muito importante, porque conforme o atleta vai evoluindo e vai aprendendo coisas novas, é importante que se tenha o fosso porque é uma estrutura de segurança para o atleta. [...] E no Flamengo também tinha o campo, tinha a piscina, eram partes do clube que a gente podia utilizar para fazer a corrida na grama, por exemplo, que não forçava tanto.

Outra ginasta também aborda essa fase de mudanças para uma infraestrutura melhor, o que aconteceu algumas vezes durante a sua carreira, saindo da Praça Oswaldo Cruz após quatro anos, indo para um colégio particular aos 10 anos, que já oferecia uma estrutura melhor e, posteriormente, passando pelo ginásio onde era então a sede da CBG, isso já aos 13 anos de idade, no bairro Portão e, finalmente, para a Universidade do Esporte:

E eu treinei dos dez aos treze anos, mais três anos nesse local (colégio) e com treze a gente foi para [...] onde era a sede da CBG (AGIPAR $\left.{ }^{11}\right)$. Eu fiquei lá dos 13 acho que aos 18 anos, dos 13 aos 17 anos, porque com 17 anos eu entrei para cá (Universidade do Esporte ${ }^{12}$ ), que foi quando a gente treinou aquele ano da Olimpíada, com as meninas aqui. Foi de 99

\footnotetext{
${ }^{11}$ Associação de Ginástica da Paraná, fundada a partir da união de escolas de Ginástica de Curitiba.

${ }_{12}$ Universidade do Esporte: centro desportivo em Curitiba, onde se localiza a sede da CBG e oferece excelentes condições de treinamento para as ginastas, como as que existem nos melhores países do mundo, em relação à $G A$.
}

para 2000 e daí em 2000 a gente foi para Olimpíada.

Sobre a estrutura dos lugares que eu treinei, na escola paranaense os aparelhos já eram bons. Não eram muito bons, mas eram melhores que aqueles da Praça Oswaldo Cruz. Então aquilo pra mim já era o máximo!

Já dava para fazer uma ginástica de alto nível, dava para fazer uma série com largada que na outra não dava, tinha fosso, duas camas elásticas (trampolim acrobático), então dava para aprender coisas mais difíceis, educativos, tinham quatro traves de equilíbrio, na outra tinha duas, então dava para ter mais meninas, tinha um solo e mais um tumbling onde a gente aprendia acrobático, salto sobre o fosso. Antes era tudo no duro (aterrissagem), neste a trave dava para ser transferida e fazer saída no fosso, a chegada também já era um ginásio de ginástica olímpica, já tinha corda, nesse já tinha espaldar então já dava para fazer o circuito, tinha minitrampolim, então tinha mais variedade, mais opções de treinar, não tinha só uma trave, uma paralela. No outro só tinha isso.

A primeira ginasta desta "geração de transição", depois de treinar com seu pai, durante cinco anos, passou por dois clubes: o Esporte Clube Pinheiros e Clube de Regatas do Flamengo, e retrata as condições de aparelhagem:

O Pinheiros não tinha um solo muito bom. O salto tinha que correr lá de fora do ginásio, junto aos associados passando. Então, tinha isso. Mas era só o solo e o salto que não eram muito bons. No Flamengo já tinha tudo, mas o solo também era todo esburacado. Não se compara à estrutura que a gente ia nos campeonatos fora do país.

Em relação às mudanças de local de treinamento, três ginastas da nova geração passaram por situação semelhante, passando por vários locais, assim como uma das ginastas pioneiras e como uma das ginastas da nova geração. Duas das ginastas da nova geração tiveram a trajetória similar à de uma das ginastas de transição, tendo a formação desportiva concentrada em um mesmo lugar até $O$ alto rendimento desportivo. Estas duas ginastas da nova geração, chegaram mais cedo a um local de treinamento com condições adequadas, e neste caso, em Curitiba, condições tidas como ideais de treinamento, conforme citado anteriormente, podendo se beneficiar a partir da etapa de especialização inicial da estrutura adequada, de aparelhos oficiais regulamentados pela FIG, tendo inclusive, mais de uma marca de equipamento à disposição, equipe multidisciplinar e técnicos estrangeiros. Segundo uma destas ginastas: 
Eu me lembro detalhadamente que as condições lá na praça eram bem precárias: não tinha aparelhagem, acho que a Camila também treinou lá na praça nesse tempo; eu, a Camila e a Ana Paula.

O ginásio que eu treinava na praça tem até hoje lá, é um cubículo, as traves todas amontoadas, não tinha solo, era pista, depois compraram um tablado daqueles bem ruinzinhos. Não tinha muita estrutura não, mas dava para a gente treinar. Nas paralelas as meninas que eram muito altas batiam os pés no teto, daí quando eu passei para o Positivo (colégio) já era melhor, era um ginásio bom, tinha fosso, tinha tudo. Na Agipar já era um ginásio bom mesmo. Já tinha toda aparelhagem, tudo igual da confederação ${ }^{13}$.

A outra ginasta desta mesma geração também fala dos mesmos espaços, com exceção do Colégio Positivo, que ela não menciona, tendo treinado na Praça Oswaldo Cruz e, em seguida, na AGIPAR para, finalmente, chegar à Universidade do Esporte:

Lá na Praça Oswaldo Cruz era uma estrutura, comparada à Universidade do Esporte agora, era bem ruim. Mas tinham todos os aparelhos, aparelhos simples, mas que a gente conseguia fazer. Não tinha problema naquela época. [...] Era uma aparelhagem bem simples. Para a nossa idade tinha estrutura! Daí na AGIPAR os aparelhos já eram bem melhores. $E$ quando começou a Seleção e a gente passou para Universidade do Esporte já foi a melhor do mundo. Tinha um Solo, três Traves, uma Paralela...

Já a terceira ginasta da nova geração passa por muitas entidades, com diferentes condições, em Ribeirão Preto, São Caetano do Sul, para em 2001, aos treze anos também ser direcionada à Universidade do Esporte como ginasta representante de Curitiba. Ela explica sua trajetória de ginásios:

Até hoje, eu vou lá (Ginásio da Cava do Bosque/Ribeirão Preto-SP). Quando eu comecei lá sempre tinha um tatame, esses tatames de judô. Às vezes a gente colocava uns colchões sarneiges do lado para fazer solo no quadrado (simulando um tablado). Tinha uma pista, que não era para o fosso, não tinha fosso. Tinha uma paralela também. Nossa! Bem crítica (risos). Tinha eu acho que umas três traves também, mas uma era melhor, que todo mundo brigava para fazer naquela (risos), e tinham duas que normalmente estavam rasgadas, então ninguém queria ir. Acho que eu fiquei uns dois anos, três, mais ou menos lá.[...].

Eu saí de um lugar para outro porque a técnica, ela quis ir, quis sair de lá porque não estava dando muito certo mesmo a estrutura. E tinha um pessoal também que fazia aeróbica e a gente tinha que dividir o ginásio às vezes,

\footnotetext{
${ }^{13}$ Ginásio sede da Confederação Brasileira de Ginástica em Curitiba naquele momento, chamado Centro de Excelência.
}

varias coisas. Ela saiu e levou a gente junto para o colégio Moura Lacerda. A gente ficou um tempo pequeno assim que eu me lembre lá. Não deve ter sido um ano. Aí a gente foi para o COC (colégio). Quando eu fui para o COC eu devia ter uns nove anos.

[...] A estrutura do COC já era bem melhor. Era trave Spieth ${ }^{14}$, paralela e salto também. Só o solo que eu acho que não era de Spieth. O treino já era bem mais forte, porque teve uma época que o COC era uma das melhores equipes do Brasil.

[...] Em São Caetano a estrutura não era muito melhor que no COC, nenhum aparelho de fora, não eram europeus, mas dava para treinar tranquilo.

A partir da primeira ginasta do grupo de ginastas de transição inicia-se uma melhoria da condição de infraestrutura oferecida pela CBG (OLIVEIRA; BORTOLETO, 2009), mais adequada ao treinamento de alto nível, chegando-se até o nível de excelência que possui atualmente, comparado aos principais países de destaque na modalidade (NUNOMURA; OLIVEIRA, 2012).

Esta primeira ginasta da geração de transição, em determinados momentos de sua preparação para os JO de 1996, realizou seus treinamentos em Curitiba, mesmo sendo atleta do Clube de Regatas do Flamengo, mas como proposta da CBG para seu aprimoramento, juntamente com seus técnicos. Mas ela ainda não chegou a usufruir da estrutura atual, realizando seus treinamentos em uma estrutura montada no Colégio Bom Jesus da Aldeia e, posteriormente, na AGIPAR, ambos em Curitiba.

Somente a partir das outras três ginastas da geração de transição, é que começam a ser beneficiadas pela infraestrutura instaurada em 1999. Portanto, todas as ginastas desde $1999 \mathrm{em}$ algum momento treinaram no ginásio da Universidade do Esporte, inicialmente em estágios de treinamento da seleção brasileira e, posteriormente, na seleção permanente ${ }^{15}$, a partir do ano de 2002. Uma das ginastas do grupo de transição e duas da nova geração foram ginastas de Curitiba e, portanto, beneficiam-se anterior e integralmente desta estrutura desde 1999. A única ginasta da nova geração não residente em

\footnotetext{
${ }^{14}$ Marca alemã de aparelhos de GA reconhecido e indicado pela Federação Internacional de Ginástica para campeonatos oficiais.

${ }_{15}$ A partir de 2002, a CBG convoca ginastas para a seleção brasileira de GA para iniciar um processo de preparação para os JO de 2004 e 2008, chamado de "seleção permanente", no qual as ginastas da seleção brasileira treinam apenas na sede da CBG, mas representam seus clubes nos campeonatos nacionais.
} 
Curitiba transfere-se para a cidade a partir de 2001 e outras duas ginastas de transição na mesma situação, somente a partir de 2002, de forma permanente.

Nesta evolução, não apenas a aparelhagem e o espaço foram melhorados, os estudos das ginastas passaram a ser realizados no próprio ginásio, assim como foi desenvolvido em países de destaque internacional na modalidade. Uma das ginastas da nova geração relata:

\begin{abstract}
Estudávamos aqui na Universidade do Esporte mesmo, onde treinávamos com professor particular. Era diferente, porque quando veio a Seleção tinham várias meninas, eu não era sozinha. Era eu e mais duas. Eram só três assim na sala. Era diferente porque... só para gente assim... E a gente estava acostumada com um monte de pessoas, mas acho que era mais legal porque a gente aprendia mais, porque ele podia dar atenção só para gente. Mas foi uma experiência bem legal assim... eu gostei. Eu tinha um professor para cada disciplina, de Geografia e História era a mesma, Biologia e Química era a mesma, Matemática e Física a mesma e tinha professora de Inglês.
\end{abstract}

Nunomura e Oliveira (2012) também abordam este assunto dos estudos das ginastas serem realizados no próprio ginásio de treinamento:

Além desta estrutura esportiva, as ginastas que cursavam o ensino fundamental e médio, atendiam às aulas no próprio CT com professores particulares, situação que possibilitava a continuidade dos estudos sem prejuízo dos treinos. Diferentemente, aquelas que cursavam 0 ensino superior eram beneficiadas com bolsas de estudo e frequentavam as aulas no período noturno (p.380).

As outras duas ginastas do grupo da nova geração relatam suas visões sobre a evolução de infraestrutura em seus depoimentos:

Com a evolução, eles foram colocando duas Paralelas, dois Solos de marcas diferentes para a gente se acostumar, porque as Copas do Mundo, cada Copa é uma aparelhagem: Spieth, $A A{ }^{16}$, American etc. $E$ a gente não se habituava, como a gente tinha só uma aparelhagem. la para a Copa e era aparelhagem diferente, era bem mais difícil. Então decidiu-se colocar dois Solos de marcas diferentes, Traves de marcas diferentes, Paralela também e Salto, para a gente se habituar aos dois aparelhos, aí dependendo da Copa, da França era aparelhagem, vamos supor Spieth, aí a gente treinava. Nos Estados Unidos é AAl, e a gente treinava na AAI.

Sobre a comparação com outros países em relação à estrutura toda e treinos, acho que agora aqui está bem parecido com o de fora,

\footnotetext{
${ }^{16}$ Marca norte-americana de aparelhos de GA reconhecido e indicado pela Federação Internacional de Ginástica para campeonatos oficiais.
}

com o pessoal de fora. O ginásio também. Acho que está tudo bem parecido. Só que o Brasil é um país muito novo na ginástica. Então, as russas, elas vieram com a ginástica deles de antes. Então eles sempre foram bons porque tiveram uma base. $E$ aqui eles começaram agora, e a gente já está bem. Imagina se a gente começasse antes. A gente podia ser um dos melhores. Acho que é mais base mesmo que falta.

Da mesma forma, Oliveira e Bortoleto (2009, p.308) corroboram os depoimentos das ginastas sobre a evolução de infraestrutura: "não podemos deixar de mencionar que atualmente a CBG e os clubes possuem uma melhor infraestrutura de aparelhos oficiais e suplementares se comparado ao período inicial do nosso estudo"17, principalmente porque a partir de 1999, houve uma preparação de infraestrutura para receber os técnicos ucranianos, posteriormente receber a seleção permanente de GAF e impulsionar esta modalidade internacionalmente, com apoio de órgãos públicos e patrocinadores.

Nunomura e Oliveira (2012) também abordam a importância da estrutura do Centro de Treinamento de Curitiba para os resultados obtidos pela GAF:

\begin{abstract}
Assegurou às ginastas aparelhos e equipamentos auxiliares dentro dos padrões internacionais. Esta condição contribuiu para a rápida evolução técnica, física e, também, psicológica, pois a qualidade dos equipamentos forneceu maior segurança no aprendizado e na execução dos elementos de risco e de dificuldade (p.382).
\end{abstract}

Neste processo de depoimentos de condições de infraestrutura na preparação desportiva de ginastas brasileiras participantes de Jogos Olímpicos, positivamente é possível notar uma transformação e um desenvolvimento nas condições pelas quais as diferentes gerações relataram passar, porém é importante destacarmos que estes depoimentos trazem informações sobre um grupo seleto de ginastas de destaque em um país de grandes dimensões territoriais, o que não representa, certamente, as condições de todo um país. Isto é possível perceber pelo resultado do estudo desenvolvido com técnicos de GA no Brasil:

De acordo com os técnicos, um país com as dimensões do Brasil necessita de vários polos de treinamento que atendam às diferentes regiões. Esta ausência de $\mathrm{CT}^{18}$ nos estados, principalmente, naqueles com tradição na modalidade também foi citado como um ponto

\footnotetext{
${ }_{17}^{17}$ Estudo realizado de 1987 a 2008.

${ }^{18}$ CT - Centro de Treinamento.
} 
negativo deste sistema centralizado em Curitiba devido ao deslocamento das ginastas para outra região. Essa polarização da modalidade gerou outro problema que, segundo os técnicos, culminou com prejuízos às instituições que desenvolviam a modalidade no Brasil (NUNOMURA; OLIVEIRA, 2012, p.384).

\section{Considerações finais}

Com base nos objetivos propostos no presente artigo de registrar e analisar as condições de infraestrutura de treinamento de ginastas brasileiras participantes de $\mathrm{JO}$ de 1980 a 2004, a contribuição deste estudo neste registro é apresentar dados até então inexistentes, pois não há qualquer registro sobre $\mathrm{o}$ assunto e sobre ginastas brasileiras com tal detalhamento, próprio do tipo de pesquisa e método escolhidos.

Ao mesmo tempo, é importante salientar que estes registros trazem a visão destas ginastas sobre o contexto vivido, portanto o estudo mostra um olhar sobre o processo, o olhar das principais ginastas do país no referido período e protagonistas das histórias de suas carreiras desportivas. Segundo Thompson (2002):

grande parte da evidência oral oriunda da experiência direta é preciosa exatamente porque não pode provir de nenhuma outra fonte. É inerentemente única. Claro que sua autenticidade pode ser avaliada. Não pode ser confirmada, mas pode ser julgada (p.307).

Alguns dados não poderão ser confirmados, mas certamente poderão ser julgados do ponto de vista da coerência interna, da conferência com outras fontes e de colocar a evidência em contexto mais amplo (THOMPSON, 2002), avaliações realizadas durante a análise cruzada dos dados.

Em relação a algumas congruências desenvolvidas nesta pesquisa, a partir dos depoimentos das ginastas brasileiras participantes em Jogos Olímpicos corroborados pela literatura apresentada, foi possível perceber um aperfeiçoamento nas condições de infraestrutura e organização desportiva a partir do início da década de 90. Este aperfeiçoamento é novamente impulsionado no final da década de 90, com o início da contratação de técnicos ucranianos, com o estabelecimento de uma seleção brasileira permanente e investimento nas condições de infraestrutura de equipamentos e ginásio visando um direcionamento aos Jogos Olímpicos de Atenas (2004) e Pequim (2008). Segundo Oliveira e Bortoleto (2009) esta transformação está diretamente relacionada ao aumento no suporte financeiro advindo do governo federal através da Lei Agnelo/Piva de 2001 e da Lei de Incentivo ao Esporte de 2006.

Essa soma de investimentos trouxe avanços significativos para um país, até então sem tradição na modalidade, que não pensava em ter uma equipe entre as melhores do mundo tão rapidamente. Foram conquistadas vagas nas Competições de "Final por Equipes"(CIV) e "Final Individual por Aparelho" (CIII), assim como medalhas em Campeonatos Mundiais, por Daniele Hypólito (CIII), Daiane dos Santos (CIII) e Jade Barbosa (Individual Geral/CII).

Foi também possível verificar que, apesar desta transformação positiva ao longo dos últimos 30 anos, em muitos momentos de suas histórias desportivas, as ginastas afirmam ter passado por treinamentos em condições de equipamentos e ginásio não adequadas ao treinamento de ginastas de alto rendimento desportivo, a partir dos parâmetros estabelecidos por documentos e pela literatura nesta pesquisa. Isto não impediu os títulos conquistados pelas mesmas, mas pode ter dificultado outros, certamente.

A partir destes depoimentos, sobre as condições de infraestrutura vividas por estas ginastas, pode-se também estabelecer relações ou verificar influências sobre outros aspectos da formação desportiva das mesmas, como a decisão sobre o encerramento da carreira de algumas destas ginastas por falta de condições de infraestrutura, assim como algumas lesões diretamente relacionadas às más condições de aparelhagem nos treinamentos (SCHIAVON, 2009).

As limitações do estudo devem-se ao fato de ser apresentada, neste artigo, a perspectiva da ginasta e não também de outros sujeitos que viveram este mesmo contexto, além dos dados representarem condições das ginastas de maior destaque no Brasil de 1980 a 2004, o que pode não retratar a realidade brasileira como um todo, não podendo, portanto, serem generalizados, mas trazendo reflexões aos profissionais do desporto e dirigentes, nos direcionamentos para que a GA seja uma modalidade de excelência no Brasil.

\section{Referências}

ARKAEV, L.I; SUCHILIN, N.G. Gymnastics: how to create champions. Oxford: Meyer \& Meyer Sport, 2004. 
BORTOLETO, M. A. C. La lógica interna de la gimnasia artística masculina (GAM) y estudio etnográfico de un gimnasio de alto redimiento. 2004. 668f. Tese (Doutorado em Educação Física). Instituto Nacional de Educación Física, Universitat de Lleida, Lleida, Espanha, 2004.

\section{CARVALHO, S. I. O discurso midiático da} ginástica artística. 2007. 102 f. Dissertação (Mestrado em Educação Física) - Universidade Católica de Brasília, Brasília, 2007.

DE BOSSCHER, V.; DE KNOP, P.; VAN BOTTENBURG, M.; SHIBLI, S.; BINGHAM, J. Explaining international sporting success: an international comparison of elite sport systems and policies in six countries. Sport Management Review, Sydney, v. 12, n. 3, p. 113-136, 2009.

DIGEL, H.. The Context of Talent Identification and Promotion: A Comparison of Nations. New Studies in Athletics, v.17, n. 3/4, p.13-26, 2002.

ENGLISH INSTITUTE OF SPORT. Disponível em:

$<$ http://www.eis2win.co.uk/pages/news searchbeg insfornewnationaldirector.aspx>. Acesso em: 12 nov. 2008.

LAVILLE, C; DIONNE, J. A construção do saber: manual de metodologia da pesquisa em ciências humanas. Porto Alegre: Artes Médicas Sul, 1999.

MEIHY, J. C. S. B. Manual de história oral. $5^{a}$. ed. São Paulo: Loyola, 2005.

NUNOMURA, M.; OLIVEIRA, M. S. Centro de excelência e ginástica artística feminina: $A$ perspectiva dos técnicos brasileiros. Motriz, Rio Claro, v.18, n.2, p.378-392, abr./jun. 2012.

OLIVEIRA, M. S.; BORTOLETO, M. A. C.. A ginástica artística masculina brasileira no panorama mundial competitivo (1987-2008). Motriz, Rio Claro, v.15 n.2 p.297-309, abr./jun. 2009.

PORTELLI, A.(1997). O que faz a história oral diferente. Projeto História (PUC-SP), São Paulo, n.14, 1997.

QUEIROZ, M. I. P. Relatos orais: do ïndivizível"ao "divizível". In: SIMSON, O. R. M. (org.).

Experimentos com histórias de vida (ItáliaBrasil). São Paulo: Vértice, Editora dos Tribunais, 1988, p. 14-43.

RIO2016. Requerimentos técnicos treinamento. Esportes olímpicos e paraolímpicos. Rio de Janeiro, 2011.

RUIZ, J. I. O.. Metodología de la investigación cualitativa. Segunda Edição. Bilbao:

Universidade de Deusto, 1999.
SCHIAVON, L. M. Ginástica Artística feminina e História Oral: a formação desportiva de atletas brasileiras participantes de Jogos Olímpicos (1980-2004). 2009. 379 f. Tese (Doutorado em Educação Física) Faculdade de Educação Física, Universidade Estadual de Campinas, CampinasSP, 2009. Disponível em: $<$ http://cutter.unicamp.br/document/?code $=00043$ 9200>. Acesso em: 31 jul. 2012.

SIMSON, O. R. M. (org.). Experimentos com histórias de vida (Itália-Brasil). São Paulo: Vértice, Editora dos Tribunais, 1988.

SIMSON, O. R. M. A arte de recriar o passado: a metodologia da História Oral e suas contribuições à promoção do envelhecimento bem sucedido. In Neri, A. (org.). Desenvolvimento e envelhecimento: perspectives biológicas, psicológicas e sociológicas. Campinas-SP: Prós, 2006.

SMOLEUSKIY, V.; GAVERDOUSKIY, I. Tratado general de gimnasia artística deportiva. Barcelona: Paidotribo, 1996.

STILL, C. Manual de Gimnasia artística femenina. Barcelona: Editorial Paidotribo, 1993.

THOMPSON, P. História oral: a voz do passado. 3‥ ed. Rio de Janeiro: Paz e Terra, 1992.

ZAKHAROV, A.; GOMES, A.C. Ciência do treinamento desportivo. $2^{\mathrm{a}}$. ed. Rio de Janeiro: Grupo Palestra Sport, 2003.

\section{Endereço:}

Laurita Marconi Schiavon Departamento de Educação Física, IB/ UNESP Avenida 24-A, 1515 Bela Vista

Rio Claro SP Brasil 13506-900

Telefone: (19) 3526-4330

e-mail: laurita@rc.unesp.br

Recebido em: 7 de janeiro de 2011.

Aceito em: 10 de dezembro de 2012.

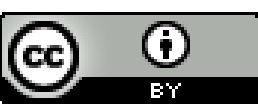

Motriz. Revista de Educação Física. UNESP, Rio Claro, SP, Brasil - elSSN: 1980-6574 - está licenciada sob Creative Commons - Atribuição 3.0 